area of the latter is doubled. In addition, the ratio of the catheter's cross-sectional area to the vessel's free flow area increases with the decreasing diameter of the vessels. Both of these account for the impressive difference in flows through the annular space, resulting in a significant reduction in oxygen supply to the extremities. This suggests that only $3.5 \mathrm{~F}$ (or smaller) catheters should be used in small newborns.

The discrepancy in results (Figures 2, 3, and 4 and Tables 1 and 2 ) between the animals in which the blood flow probe was used and the animals without the blood flow probe can be attributed to the initial vasospasm produced by placement of the probe around the vessel. In these animals, a smaller flow obstruction would produce a more pronounced decrease in $\mathrm{BF}$ and $\mathrm{O}_{2} \mathrm{a}$.

Clinically, various sites have been suggested for catheter placement $(1,6,11)$. Our data indicate that there is no change in oxygen supply to the opposite extremity when the catheter is placed below the aortic bifurcation, suggesting that this is a preferred site. This concurs with recent reports by others $(4,10)$. Size and site of a catheter and size of blood vessels should be considered during the clinical application of umbilical artery catheters. Undesirable changes could be detected by continuous monitoring of extremity $\mathrm{O}_{2} \mathrm{a}$ or differential core and extremity $\mathrm{T}$.

\section{SUMMARY}

Placement of catheters in the abdominal aorta produces an obstruction which is manifested by decreased extremity blood flow, muscle oxygen availability, and temperature, and which is greater with $5.0 \mathrm{~F}$ catheters and more pronounced in animals weighing less than $1.6 \mathrm{~kg}$.

Placement of the catheter below the aortic bifurcation did not produce any change in blood flow and oxygenation of the contralateral extremity, suggesting that this is a preferred site. These and other complications could be detected by differential monitoring of extremity and core temperature or extremity tissue oxygen availability.

\section{REFERENCES AND NOTES}

1. Baker, D. H., Berdon, W. E., and James, L. S.: Proper localization of umbilical artery and venous catheters by lateral roentgenograms. Pediatrics, 43: 34 (1969).

2. Beran, A. V., Strauss, J., Brown, C. T., and Katurich, N.: A simple arterial occluder. J. Appl. Physiol. 24: 838 (1968).

3. Beran, A. V., Strauss, J., Sperling, D. R., Norton, A. C., Garwood, V. P., and Yamazaki, J.: Effect of Thalidomide on brain oxygenation. Pediat. Res., 5: 199 (1971).

4. Book, L. S., Herbst, J. J., and Atherton, S.: Gluteal necrosis and gastrointestinal bleeding: Complications of $\mathrm{Ca}$ gluconate infusion through umbilical artery catheterization. Clin. Res., 23: 157 (1975).

5. James, L. S.: Biochemical aspects of asphyxia at birth. In: Adaptation to Extrauterine Life. Report of the 31 st Annual Ross Conference on Pediatric Research, Vancouver, British Columbia, 1959 (Ross Laboratories, Columbus, Ohio, 1959).

6. James, L. S.: Complications arising from catheterization of the umbilical vessels. In: Problems of Neonatal Intensive Care Units. Report of the 59th Ross Conference on Pediatric Research, Stowe, Vermont, 1969 (Ross Laboratories, Columbus, Ohio, 1969).

7. Kitterman, J. A., Phibbs, R. H., and Tooley, W. H.: Catheterization of umbilical vessels in newborn infants. Pediat. Clin. N. Amer., 17: 895 (1970).

8. Lackey, D. A., and Taber, P.: An unusual complication of umbilical artery catheterization. Pediatrics, 49: 281 (1972).

9. Moss, A. J., Adams, F. H., O'Loughlin, B. J., and Dixon, W. J.: The growth of normal aorta and of the anastomotic site in infants following surgical resection of coarctation of the aorta. Circulation, 19: 338 (1952).

10. Powers, W. F., and Swyer, P. R.: Limb blood flow following umbilical arterial catheterization. Pediatrics, 55: 248 (1975).

11. Vidyasagar, D., Downes, J. J., and Boggs, T. R.: Respiratory distress syndrome of newborn infants. II. Technic of catheterization of umbilical artery and clinical results of treatment of 124 patients. Clin. Pediat., 9: 332 (1970).

12. This work was partially supported by the National Institutes of Health, National Heart and Lung Institute Contract N01 5-2947.

13. Requests for reprints should be addressed to: R. F. Huxtable, M.D., Department of Pediatrics, University of California, Irvine, California College of Medicine, Irvine, Calif. 92717 (USA).

14. Accepted for publication January 28, 1976.

\title{
A Comparison of the Active Stiffness of Fetal and Adult Cardiac Muscle
}

\author{
RICHARD A. McPHERSON, MARTHA F. KRAMER, JAMES W. COVELL, AND \\ WILLIAM F. FRIEDMAN ${ }^{19}$ \\ Departments of Pediatrics, Pathology, and Medicine, University of California, San Diego, School of Medicine, \\ La Jolla, California, USA
}

Extract

This report describes the in vitro analysis of the series elasticity of ventricular myocardium isolated from five fetal lambs and six adult sheep. Active compliance measurements were obtained by quick releases utilizing a closed loop servosystem and electromagnetic positioning device to control cardiac muscle length or tension. Right ventricular moderator bands were obtained from five fetuses (average 139 days of gestation, term $=147$ days), and compared with two adult moderator bands and four adult right ventricular trabeculae carneae. After correction for equipment coupling, the experimental load extension data were fit to an exponential expression by a least squares technique: $\operatorname{strain}=1 / b \ln (I+$ stress $/ \mathbf{a})$.

When fetal and adult data were compared, no age-related differences in the constants were observed $(a=0.185 \pm 0.062 \mathrm{SE}$ (fetal) and $0.159 \pm 0.03 \mathrm{~g} / \mathrm{mm}^{2}$ (adult); $\mathrm{b}=\mathbf{4 0 . 4} \pm 5.2$ (fetal) and $43.1 \pm 5.2$ (adult); and $a b=7.39 \pm 2.34$ (fetal) and $5.27 \pm .99$ (adult). However, significant variation existed in the histologically determined amount of contractile tissue present in muscle samples from both fetus $(57-85 \%$, average $=74.0 \pm 4.9)$ and adult 
$(64-94 \%$, average $=82.3 \pm 5.3)$. Without regard to age, a significant correlation was found between the b stiffness constant and the amount of contractile mass present in cardiac muscle. Thus, it is concluded that there is no age-related difference in the stiffness of fetal and adult ventricular muscle. However, there is a significant relationship between active compliance and true muscle mass.

\section{Speculation}

There is now substantial evidence that isometric force generation in fetal ventricular myocardium is significantly depressed when compared with the adult (3).Moreover, this reduction in the strength of cardiac contraction is not accompanied by a comparable depression in the extrapolated or unloaded velocity of shortening when fetal and adult hearts are compared (3). Several hypotheses have been advanced to explain the depression of force generation in fetal tissue. First, it is clear that there is less contractile tissue per unit volume in fetal myocardium $(3,13)$; second, a depression of contractile state may exist in fetal cardiac muscle (3). Although the additional contractile tissue present in the adult heart could explain the lesser force generation of fetal myocardium, it is also possible that a more compliant "series elasticity" in fetal muscle could be responsible for an attenuation of force generation, particularly since the unloaded velocities are similar in the two groups of muscle. Indeed, the resting length-tension relationship of fetal muscle (3) and the non-normalized pressure-volume relationship of the whole heart $(7,13)$ have been shown to be significantly "stiffer" than in adult preparations, although the resting stiffness per unit mass of tissue may not be altered (7). Accordingly, the present study was designed to examine the active compliance of fetal and adult sheep myocardium in order to determine whether age-related differences exist in "series elasticity" or active stiffness.

It is clear that an understanding of the changes in cardiovascular structure and function that accompany growth is a prerequisite to a proper comprehension of the clinical consequences of congenital heart lesions throughout life. It has been shown that many intrinsic structural and mechanical properties of heart muscle may be age dependent. Accordingly, the objective of the studies described in the present report was to define more clearly the active compliance characteristics of the developing heart.

\section{MATERIALS AND METHODS}

Hearts of six adult sheep were removed after rapid midsternotomy under sodium pentobarbital anesthesia $(5 \mathrm{mg} / \mathrm{kg}$ iv $)$. Five fetal lamb hearts (133-149 days gestational age, average $=139$ days, term $=147$ days) were obtained after hysterotomy of ewes of mixed Western breeds with timedated pregnancies. Under spinal anesthesia ( $1 \%$ tetracaine hydrochloride, 4-6 cc) the uterus was exteriorized through a midline abdominal incision, and the fetus delivered rapidly. A left thoracotomy was performed and the fetal heart removed. Both fetal and adult hearts were treated identically after cardiectomy. The right ventricular moderator band or trabecular muscle was excised rapidly without stretching the muscle. Muscles were attached by silk string to stainless steel wires connected to length and tension transducers in a horizontal myograph containing oxygenated, buffered Krebs-Ringer solution at $\mathrm{pH} 7.4$ and $30^{\circ}$.

The horizontal myograph and quick release system have been previously described in detail (9). In brief, the tension transducer (Kongisberg model F-2) was mounted firmly to the chassis of the myograph to form a rigid support for one end of the muscle. The other end of the muscle was connected to the base of a pendulum. A short extension of the pendulum beyond its fulcrum intersected a beam of light directed at a photodiode which transduced pendulum position. The control of muscle length and tension was accomplished by a closed loop servomechanism which utilized an electromagnetic device for positioning of the pendulum, an analog computer (Electronics Associates, Inc., model 580) for calculating error signals, and a small digital computer (Electronics Associates, Inc., model 640) to control experimental protocol. The muscle was stimulated electrically at $12 / \mathrm{min}$ with square wave pulses $(3.7$ msec duration) $10 \%$ above threshold by platinum electrodes parallel to the muscle. Recordings of length and tension were made with a Brush-Clevite model 260 recorder at $125 \mathrm{~mm} / \mathrm{sec}$.

Isolated muscle was stimulated to contract isometrically at low preload until peak tension stabilized (1-2 hr). $\mathrm{L}_{0}$ (resting length) was measured directly at that length at which no force developed under isometric stimulation. Length-tension curves were obtained using computer control and were repeated until $\mathrm{L}_{\max }$ was within $10 \%$ on two trials. The computer protocol was then changed to the quick release $(\mathrm{QR})$ program (9). Each run began with a 10 -beat equilibration period and was followed by 5-10 QR beats alternating with isometric contractions. Preload was set corresponding to an initial length $\left(\mathrm{L}_{1}\right)$ of $24-48 \% \mathrm{~L}_{\max }$ as determined by the previous length-tension curve. Percentage $\mathrm{L}_{\max }$ was calculated as $\left(\mathrm{L}_{\mathrm{i}}-\right.$ $\left.\mathrm{L}_{0}\right) /\left(\mathrm{L}_{\max }-\mathrm{L}_{0}\right) \times 100 \%$. All quick releases were initiated at the time of peak tension development. The first release in a run was to a tension approximating preload. Succeeding release tensions were automatically incremented to higher levels set by the computer program. Both single and paired pacing were utilized to provide comparable levels of active tension over which releases were reproducible and accurately measured in both fetal and adult tissue.

To determine the compliance of the suture material and physical system exclusive of muscle, quick releases were performed with cardiac muscle replaced by a rigid metal staple. The system was passively stretched to peak tension and released to successively different after tensions. The data so obtained were fit (by an iterative Gaus-Newton method) to the equation

$$
\Delta \mathrm{L}_{\mathrm{s}}=\mathrm{k}\left(\mathrm{e}^{\mathrm{m} \Delta \mathrm{Fs}}-1\right)
$$

where $\Delta \mathrm{L}_{s}$ (in millimeters) is change in string length observed for the imposed change in tension $\lrcorner \mathrm{F}_{\mathrm{s}}$ (in grams). The constants were found to be $k=0.0342$ and $m=0.529$. Using these constants, correction for equipment compliance was accomplished by subtracting calculated length change from observed muscle and system length change for an imposed tension change (designated hereafter as $\triangle \mathrm{L}$ and $\Delta \mathrm{F}$ ) (Fig. 1).

The experimental situation necessitates that release of a muscle be from a higher tension to a lower tension in order to measure a phenomenon occurring within the transitory active state. However, the analysis of series elasticity is in terms of incremental stretches from lower tension upwards, i.e., the increasing amount of stretch obtained from a spring by increasing afterload. In order to make the transformation from a set of data points to that of an exponential spring, a point of reference in length-tension coordinates was chosen as maximum length change $\left(\Delta \mathrm{L}_{\max }\right)$ corresponding to the tension change $\left(\Delta \mathrm{F}_{\max }\right)$ of a release from peak active tension to resting tension. $\lrcorner \mathrm{L}_{\max }$ was obtained by extrapolation of existing data in those runs where initial release did not fall to preload. Thus, to evaluate the actual load and extension relationship operative during an individual quick release, $\lrcorner \mathrm{L}$ and $\lrcorner \mathrm{F}$ for that release were subtracted from $\lrcorner \mathrm{L}_{\max }$ and $\lrcorner \mathrm{F}_{\max }$ and the differences designated as $\mathrm{L}$ and $\mathrm{F}$. These values were normalized to allow comparisons of fetal and adult muscle by dividing $\mathrm{L}$ by $\mathrm{L}_{\mathrm{i}}$ (the preloaded length of the muscle) and $\mathrm{F}$ by $\mathrm{A}_{i}$ (the calculated cross-sectional area of the muscle at its preload length) $(4,12)$. Finally, by means of an iterative Gauss-Newton method of curve fitting, the constants $a$ and $b$ were determined by the following equation (4)

$$
\mathrm{L} / \mathrm{L}_{\mathrm{i}}=\frac{1}{\mathrm{~b}} \ln 1+\frac{\mathrm{F} / \mathrm{A}_{\mathrm{i}}}{\mathrm{a}}
$$

The units of a are grams per $\mathrm{mm}^{2}$ and the units of $\mathrm{b}$ are millimeters of initial length per mm extension.

At the end of each experiment, the muscle was weighed and fixed in $10 \%$ formaldehyde for histologic evaluation. Sections were 
made longitudinally through the muscle at four equidistant positions. The sections were stained with hematoxylin and eosin, and with Masson trichrome for identification of elastic fibers and improved discrimination of contractile from noncontractile tissue. At high power fields $(\times 400)$ each histologic section was scored for interspace (artifacts of tissue shrinkage), nonmuscle, and muscle at crosspoints in a grid (42 points). Four to five fields per section were scored in a regular overlapping pattern; the contractile mass calculated as a percentage of the total contractile and noncontractile tissue points observed.

\section{RESULTS}

Tracings of representative quick released contractions are shown in Figure 1 (panels $A-D$ ) and the stress-strain relationship determined from these contractions (indicated by the letter of the contraction) is shown in the lower two panels. A plot of string length changes and system compliance for imposed quick release tension changes is also included (1). The curve for string and system compliance is subtracted from the curve of the raw data ( ) and a "corrected curve" $(\mathbf{\Delta})$ is obtained which relates the length change for an increment in force for the muscle. In this and other experiments, system compliance contributed less than $10 \%$ of total compliance at higher force changes. The resulting stress-strain relationship was adequately described by the exponential relationship shown in the bottom right hand panel (Equation 2).

Data was analyzed from four fetal and five adult muscles of

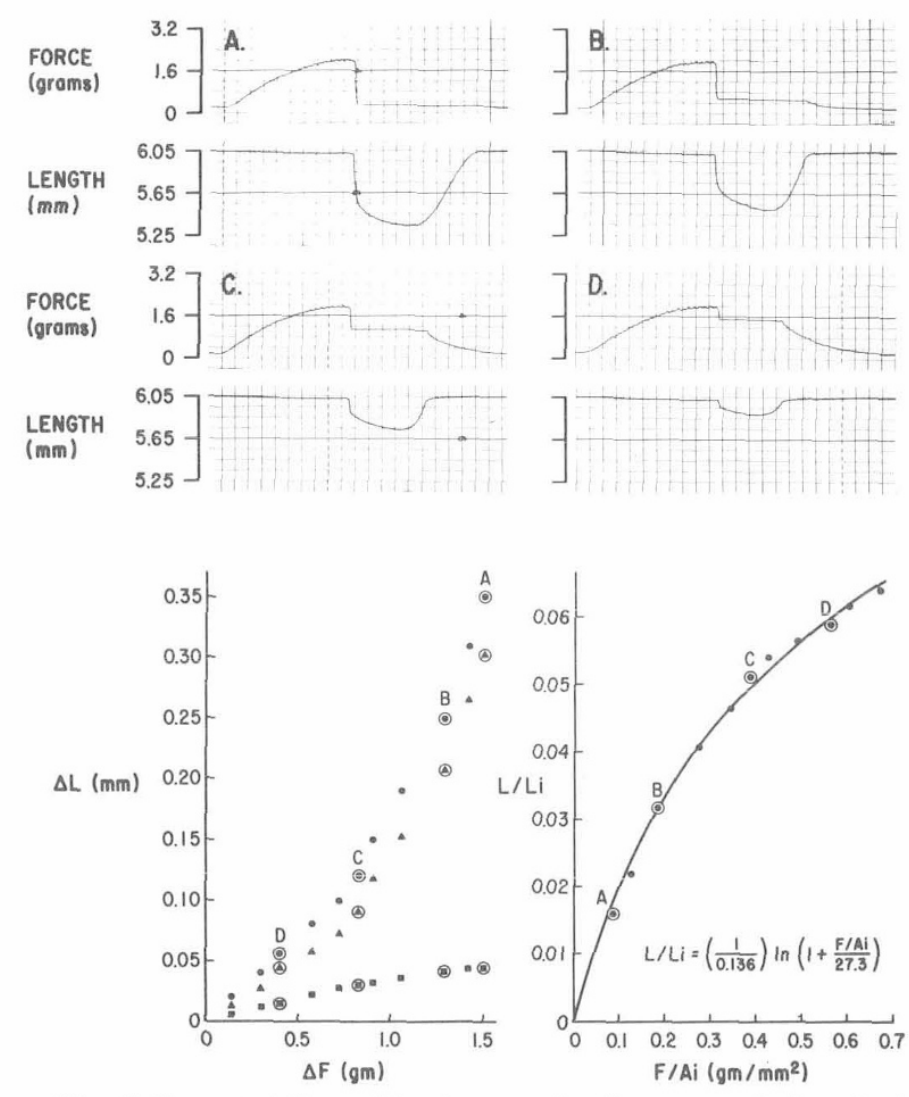

Fig. 1. Representative quick-release contractions on a single animal (sheep 20, run 7) and calculation of stress-strain relationship. The paired tracings of force and length $(A, B, C$, and $D)$ in the upper panel demonstrate the effect of altering quick release afterload on quick release length change (large square is $80 \mathrm{msec}$ ). These and other values of length and tension change $(\Delta L$ and $\Delta F)$ are plotted in the lower left panel ( ) System compliance (⿴囗十) is plotted and subtracted from the raw data to yield the "corrected curve" ( $\mathbf{A})$ representing solely muscle length change. The lower right hand panel is the final calculated stress-strain relationship during muscle contraction, normalized for initial resting length $(L i)$ and initial cross-sectional area $(A i)$. matched cross-sectional area and comparable levels of relatively low preload ( $24-48 \% \mathrm{~L}_{\max }$ ) (Table $\left.\mathrm{I}\right)$. The data were generated by two to four runs at the given preloads in each muscle. Since no significant difference existed in the stress-strain relationship in any animal when paired or single stimulation was employed (paired: a $=0.069 \pm 0.015 ; \mathrm{b}=36.6 \pm 4.12$; single: $\mathrm{a}=0.130 \pm 0.038 ; \mathrm{b}=$ $40.7 \pm 5.40$ ), both single and paired stimulation runs were treated similarly. By rearranging and differentiating Equation 2 it can be seen that the constant $b$ relates to the slope of the relationship between $\mathrm{dF} / \mathrm{dL}$ and force, whereas the term ab relates to the intercept. As shown in Table 1, there was no significant difference in $a, b$, or $a b$ when fetal and adult muscles were compared. Thus, stiffness represented by $\mathrm{dF} / \mathrm{dL}$ was not significantly different in these two groups of muscle.

Figure 2 shows the calculated average series elasticity relationships for adult and fetal muscle. Although the average fetal data appear to lie slightly below and to the right of the adult relationship, this difference was not statistically significant.

Calculation of the percentage of contractile tissue contained in each muscle showed that moderator bands have significantly less muscle content than trabeculae carneae (average $71.7 \pm 3.7 \%$ for moderator bands vs. $90.4 \pm 2.0 \%$ for trabeculae carneae; $p<$ 0.005 . However, the adult moderator bands used in this study were found to contain essentially the same muscle content as fetal moderator bands $($ adult $=66.0 \pm 1.6 \%$, fetal $=74.0 \pm 4.9 \%$ ). These results compare favorably with earlier findings (15) on the composition of sheep moderator bands. The distribution of contractile tissue in all fetal muscles $(74.0 \pm 4.9 \%)$ was not significantly different from that in all adult muscles (moderator band and trabeculae carneae combined; $82.3 \pm 5.3 \%$ ). Therefore, in examining age-related differences the latter muscle types were treated as a single category of adult muscle.

As shown in Figure 3, values of the constant b averaged for each of the comparable runs in fetal and adult muscle were significantly related to the amount of contractile tissue present in each muscle, irrespective of age. The correlation coefficient between percent muscle tissue and b was $0.757(p<0.01)$. Neither a nor ab showed a significant linear relationship with percentage of muscle tissue.

In order to evaluate the influence of cross-sectional area and resting stress on this correlation between $b$ and percentage of muscle tissue (i.e., through a possible spurious cross correlation), the partial correlation coefficient was calculated for $b v s$. percentage of muscle tissue (MT) while holding constant both cross-sectional area (CSA) and resting stress (RS) (14). This correlation coefficient ( $\mathrm{r}_{\mathrm{b}} \%$ MT.CSA RS $)$ has a value of 0.666 which is significant at the $p=0.05$ level.

\section{DISCUSSION}

The findings of the current study reveal a broad range of muscle stiffness in both adult and fetal myocardium. Differences in active compliance appear to be related to muscle content rather than to the maturity of the muscle. In both the fetus and adult, quick release data demonstrated an exponential relationship between stress and strain. Data at any age, when compared over a similar range of muscle lengths, could be closely approximated by an exponential relationship utilized commonly to describe series elasticity in other cardiac muscle $(4,12)$. Moreover, the stressstrain relationships for fetal and adult muscle were not significantly different. Thus, from the results of this study it does not appear likely that the differences observed in isometric tension development between fetal and adult myocardium (3) can be explained by an important difference in active compliance.

However, the data do indicate that there are differences in stiffness of fetal and adult muscle that appear to relate primarily to the amount of contractile tissue present in fetal and adult myocardium. These results support the concept that there may be series elasticity located within the muscle myofilaments as suggested by Civan and Podolsky (2) and Huxley and Simmons $(5,6)$.

Evidence exists that the quick release technique for the determination of series elasticity may deactivate the contractile element to 
Table 1. Muscle parameters and calculated constants for each fetal and adult muscle ${ }^{1}$

\begin{tabular}{|c|c|c|c|c|c|c|c|c|}
\hline $\begin{array}{l}\text { Sheep no./ } \\
\text { Muscle type }\end{array}$ & $\begin{array}{l}\% \mathrm{~L}_{\max } \\
\text { for quick } \\
\text { release }\end{array}$ & $\mathrm{a}, \mathrm{g} / \mathrm{mm}^{2}$ & $\begin{array}{l}\mathrm{b} \text {, inverse } \\
\text { strain }\end{array}$ & $a b$ & $\begin{array}{c}\text { Peak active } \\
\text { tension at } \\
\mathrm{L}_{\max }, \mathrm{g} / \mathrm{mm}^{2}\end{array}$ & $\begin{array}{l}\text { \% Muscle } \\
\text { tissue }\end{array}$ & $\begin{array}{l}\text { Cross-sectional } \\
\text { area at } \mathrm{L}_{\max } \\
\mathrm{mm}^{2}\end{array}$ & $\begin{array}{l}\text { Resting stress } \\
\text { at } \mathrm{L}_{\mathrm{i}}, \mathrm{g} / \mathrm{mm}^{2}\end{array}$ \\
\hline \multicolumn{9}{|l|}{ Fetal data } \\
\hline $10 / \mathrm{MB}$ & 48.2 & 0.391 & 26.8 & 10.5 & 2.64 & 57.0 & 0.715 & 0.306 \\
\hline $11 / \mathrm{MB}$ & 43.7 & 0.260 & 57.4 & 14.9 & 0.758 & 79.2 & 3.23 & 0.155 \\
\hline $13 / \mathrm{MB}$ & 24.2 & 0.134 & 36.5 & 5.85 & 3.70 & 70.1 & 1.65 & 0.095 \\
\hline $14 / \mathrm{MB}$ & 30.3 & 0.082 & 35.3 & 2.97 & 1.03 & 85.1 & 2.46 & 0.081 \\
\hline $18 / \mathrm{MB}$ & 47.8 & 0.059 & 46.2 & 2.74 & 1.08 & 78.7 & 3.69 & 0.156 \\
\hline Average & 38.8 & 0.185 & 40.4 & 7.39 & 1.84 & 74.0 & 2.35 & 0.158 \\
\hline$\pm \mathrm{SE}$ & 4.9 & 0.062 & 5.2 & 2.34 & 0.57 & 4.9 & 0.54 & 0.039 \\
\hline \multicolumn{9}{|l|}{$\begin{array}{c} \pm \mathrm{SE} \\
\text { Adult data }\end{array}$} \\
\hline $6 / \mathrm{TC}$ & 40.1 & 0.082 & 45.2 & 3.68 & 0.789 & 93.3 & 3.32 & 0.107 \\
\hline $8 / \mathrm{TC}$ & 42.0 & 0.061 & 50.0 & 3.10 & 1.15 & 94.0 & 3.04 & 0.037 \\
\hline $9 / \mathrm{MB}$ & 41.0 & 0.186 & 28.6 & 4.96 & 1.51 & 64.4 & 1.38 & 0.177 \\
\hline $15 / \mathrm{TC}$ & 46.9 & 0.216 & 50.6 & 9.84 & 1.46 & 85.7 & 1.54 & 0.147 \\
\hline $17 / \mathrm{TC}$ & 31.8 & 0.247 & 57.5 & 5.72 & 1.14 & 88.6 & 1.07 & 0.595 \\
\hline $20 / \mathrm{MB}$ & 43.3 & 0.162 & 26.6 & 4.30 & 0.561 & 67.6 & 1.71 & 0.170 \\
\hline Average & 40.9 & 0.159 & 43.1 & 5.27 & 1.10 & 82.3 & 2.01 & 0.205 \\
\hline$\pm \mathrm{SE}$ & 2.1 & 0.030 & 5.2 & 0.99 & 0.15 & 5.3 & 0.38 & 0.080 \\
\hline$p$ & NS & NS & NS & NS & NS & NS & NS & NS \\
\hline
\end{tabular}

${ }^{1} \mathrm{~L}_{\mathrm{i}}$ : initial resting length; MB: moderator bands; TC: trabeculae carnae.

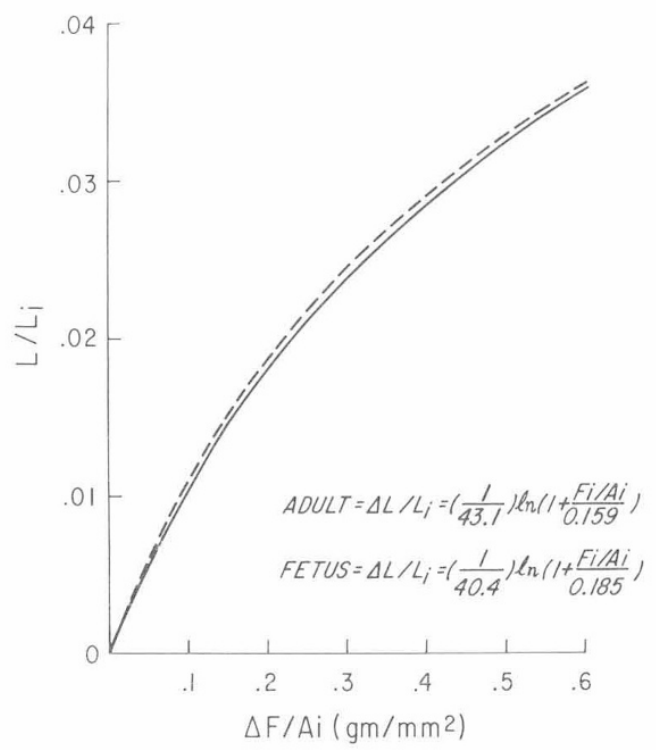

Fig. 2. Comparison of active stress-strain relationship in adult and fetal myocardium calculated with average values of constants a and $\mathrm{b}$ for each age group. $L_{i}$ : initial resting length; $A_{i}$ : initial cross-sectional area.

some extent and lead to spurious results when contractile state is examined immediately after quick release $(1,8)$. Furthermore, the stress-strain relationship determined over broad ranges of force may be initial length dependent $(10-12)$. In the present study, care was taken to examine fetal and adult cardiac tissue in the same muscle length range relative to the length-tension curve, and over the same ranges of force. Thus, it is unlikely that these difficulties with the quick release technique could influence the comparison between fetal and adult muscle. Whether or not fetal/adult differences exist in the sensitivity to deactivation with quick release is conjectural.

\section{SUMMARY}

The active compliance of isolated fetal and adult cardiac muscle appears to be quite similar. Thus, an age-related difference in this

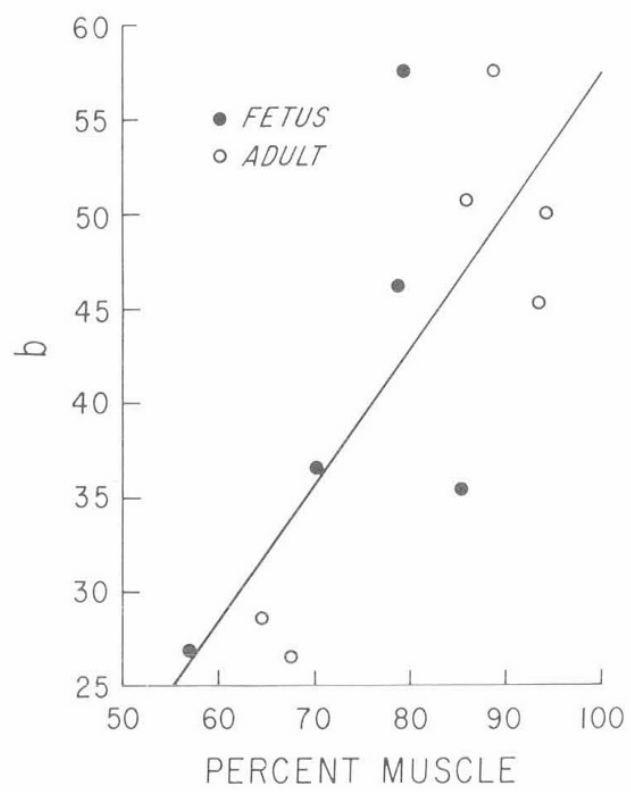

Fig. 3. Dependence of the constant $\mathrm{b}$ on the content of contractile mass independent of age group.

intrinsic mechanical property of the myocardium does not provide an explanation for the attenuation of force development observed in fetal cardiac tissue. However, the current results also indicate that active myocardial stiffness may be related to the amount of contractile tissue present in heart muscle. It should be recognized that moderator band and trabecular muscles represent only a small portion of the whole heart's functional contractile tissue at any age. To the extent that important reductions appear to exist in muscle protein content per unit volume in the entire fetal ventricle, the present results would also support the possibility that the whole fetal heart may be more actively compliant than the adult. Thus, a lesser fetal cardiac contractile/noncontractile mass relationship, when compared with the adult, would be expected to attenuate the stress development of the whole fetal heart directly, as well as indirectly by virtue of altering its active stiffness properties. 


\section{REFERENCES AND NOTES}

1. Brady, A. J.: Active state in cardiac muscle. Physiol. Rev., 48: 570 (1968).

2. Civan, M. M., and Podolsky, R. J.: Contraction kinetics of striated muscle fibers following quick changes in load. J. Physiol., 184: 511 (1966).

3. Friedman, W. F.: The intrinsic physiologic properties of the developing heart. Progr. Cardiovasc. Dis., 15: 87 (1972).

4. Hefner, L. L., and Bowen, T. E.: Elastic components of cat papillary muscle. Amer. J. Physiol., 212: 1221 (1967)

5. Huxley, A. F., and Simmons, R. M.: Mechanical properties of the cross-bridges of frog striated muscle. J. Physiol., 218: 59P (1971).

6. Huxley, A. F., and Simmons, R. M.: Proposed mechanism of force generation in striated muscle. Nature, 233: 533 (1971).

7. Lee, J. C., and Downing, S. E.: Left ventricular distensibility in newborn piglets, adult swine, young kittens, and adult cats. Amer. J. Physiol., 226: 1484 (1974).

8. McLaughlin, R. J., and Sonnenblick, E. H: Time behaviour of series elasticity in cardiac muscle: Real-time measurement by controlled-length techniques. Circ. Res., 34: 798 (1974).

9. McPherson, R. A., Lavelle, J. F., Friedman, W. F., and Covell, J. W. A technique for the automated analysis of cardiac muscle function. Comp. Biomed. Res., 5: 684 (1972)

10. Meiss, R. A., and Sonnenblick, E. H.: Controlled shortening in heart muscle. Velocity-force and active-state properties. Amer. J. Physiol., 222: 630 ([972).
11. Parmley, W. W, and Sonnenblick, E. H. Mechanical effects of increased series elasticity. Amer. J. Cardiol., 27: 376 (1971).

12. Parmley, W. F., and Sonnenblick, E. H.: Series elasticity in heart muscle: Its relation to contractile element velocity and proposed muscle models. Circ. Res., 20: 112 (1967)

13. Romero, T., Covell, J. W., and Friedman, W. F.: A comparison of pressurevolume relations of the fetal, newborn and adult heart. Amer. J. Physiol., 222: 1285 (1972).

14. Snedecor, G. W., and Cochran, W. G.: Statistical Methods (lowa State University Press, Ames, Iowa, 1967).

15. Truex, R. C., and Copenhaver, W. M.: Histology of the moderator band in man and other mammals with special reference to the conduction system. Amer. J. Anat., 80: 173 (1947)

16. Dr. J. W. Covell is recipient of National Heart and Lung Institute Career Development Award HE 21132

17. Dr. W. F. Friedman is recipient of National Heart and Lung Institute Career Development Award HE 41737

18. This research was supported by National Institutes of Health Program Project Grant HL 12373 and Graduate Training Grant HL 05846.

19. Requests for reprints should be addressed to: W. F. Friedman, M.D., Chief of Pediatric Cardiology, University Hospital, 225 W. Dickinson St., San Diego, Calif. 92103 (USA).

20. Accepted for publication January 28, 1976.

\title{
Bile Pigments in Humans and in Nonhuman Primates during the Perinatal Period: Composition of Meconium and Gallbladder Bile of Newborns and Adults
}

\author{
SHULA G. BLUMENTHAL, RICHARD M. IKEDA, AND BORIS H. RUEBNER ${ }^{26}$ \\ Department of Pathology, School of Medicine, University of California, and Primate Research Center, \\ Davis, California, USA
}

\section{Extract}

Meconium of human infants and rhesus monkey infants (Macaca mulatta) contained only about 0.10 of the amount of bilirubin in gallbladder bile of the same individuals.

Ninety-nine percent of the bilirubin in adult bile was conjugated. The proportion of conjugated bilirubin in infant bile and meconium was only slightly lower. Adult bile contained more bilirubin diconjugates than monoconjugates, whereas only $20 \%$ of the bilirubin in infant bile and meconium was in the form of diconjugates.

The predominant azopigment in adult bile was azopigment $\delta$ (a glucuronide). Infant bile contained less azopigment $\delta$, more azopig ment $\alpha$ (azodipyrrole), and a so far unidentified conjugated azopig ment (azopigment $\beta$ ). Azopigment $\beta$ was also found in meconium but adult gallbladder bile contained only trace amounts of this pigment.

\section{Speculation}

The metabolism of pigments in human meconium and bile is not yet well understood. To learn more about this area an animal model is required. In this investigation the pigments in adult human bile, infant bile, and meconium were compared with corresponding specimens from nonhuman primates. Our aim was to study the suitability of such an animal model for an investigation of this aspect of neonatal bilirubin metabolism.

The metabolism of bilirubin in adult primates and other animals is relatively well understood $(1,7)$, whereas that of newborns and fetuses is more controversial $(2,15,23)$. Hepatic glucuronyl transferase activity in fetal and newborn humans has been demonstrated $(13,15)$. However, it is not yet established whether the same transferase is responsible for the production of monoconjugates and diconjugates, nor is the specificity of glucuronyl transferase for substrates other than glucuronides established. Conjugation of exogenous and endogenous substrates in the fetus at term was found to be less efficient than in adults, and to increase soon after birth $(8,14,16,22)$. In the fetal dog hepatic conjugation of bilirubin and excretion into the intestine appeared to be the principal mechanism of bilirubin elimination (23). In fetal monkeys transfer of unconjugated bilirubin across the placenta predominated $(2,21)$. Conjugated bilirubin administered to monkey fetuses, however, was not transferred across the placenta in significant amounts (17). Even in primates, some bilirubin (ap- 